\title{
The Efficacy of Rapid Diagnostic Test in the Diagnosis of Malaria among Adults as Compared to Microscopy in a Hospital in Imo State, South Eastern Nigeria
}

\author{
Ugonma Winnie Dozie*, Nneka Augusta Ekeh, Gregory Ndubeze Iwuoha, \\ Chidozie Joakin Nwaokoro, Nneka Eleano Asuzu, Ikechukwu Nosike Simplicius Dozie \\ Department of Public Health, Federal University of Technology, Owerri, Nigeria \\ Email: *ugonmadozie@gmail.com
}

How to cite this paper: Dozie, U.W., Ekeh, N.A., Iwuoha, G.N., Nwaokoro, C.J., Asuzu, N.E. and Dozie, I.N.S. (2020) The Efficacy of Rapid Diagnostic Test in the Diagnosis of Malaria among Adults as Compared to Microscopy in a Hospital in Imo State, South Eastern Nigeria. Open Access Library Journal, 7: e6528.

https://doi.org/10.4236/oalib.1106528

Received: June 15, 2020

Accepted: July 25, 2020

Published: July 28, 2020

Copyright $\odot 2020$ by author(s) and Open Access Library Inc.

This work is licensed under the Creative Commons Attribution International License (CC BY 4.0).

http://creativecommons.org/licenses/by/4.0/

\begin{abstract}
Malaria has been noted to be one of the most prevalent diseases affecting mankind. Diagnosis is based on clinical assessment using microscopy and recently by rapid diagnostic tests (RDTs). The objective of this study was to ascertain the efficacy of RDT to microscopy in the identification of malaria parasite among adults attending a hospital in Owerri, Imo State. A cross-sectional study was carried out using 110 consenting outpatients of a hospital in Imo state, Nigeria. Results of the study showed that more respondents were females 63 (57.3\%). Microscopy was positive in 97.3\% (107) patients, and RDT was positive in $100 \%$ (32) of the adult, while $2.7 \%$ of those negative by microscopy were also negative with RDT. There was no significant difference when the accuracy of both tests was compared $\left(\mathrm{P}=0.261, \chi^{2}=\right.$ 1.262). The RDT used had a sensitivity of $29.9 \%$, a specificity of $100 \%$. The positive predictive value was $100 \%$ and the negative predictive value $3.85 \%$. The microscopy performance was extremely high compared to RDT in the diagnosis of malaria in adults. Microscopy is recommended, if available to be done for all patients suspected of having malaria with negative RDT in other not to miss out people with the disease as it remains the gold standard for malaria diagnosis.
\end{abstract}

\section{Subject Areas}

Epidemiology

Keywords

Malaria, Efficacy, Rapid Diagnostic Test, Microscopy 


\section{Introduction}

Malaria has been noted to be one of the most infectious diseases affecting mankind which differs in its epidemiology and clinical manifestations in various parts of the globe. Variable factors including mosquito vector efficiency and distribution, climate, environmental and climatic conditions as well as state of acquired immunity of the exposed individuals contribute to wide distribution of malaria [1]. Early and accurate identification of malaria diagnosis is a key to the successful control of malaria which will in turn reduce malarial illness and death while avoiding the unnecessary use of antimalarial drug. Worldwide effect of malaria has lead to increased interest in the development of effective diagnostic successful control of malaria which will in turn reduce malarial illness and death while avoiding the unnecessary use of antimalarial drug. Worldwide effect of malaria has lead to increased interest in the development of effective diagnostic strategies both in developing countries where the burden of malaria is high as well as developed countries where expertise in malaria diagnosis is relatively scarce [2].

World Health Organization in 2010 suggested patients that are suspected to have malaria should be tested for malaria prior to treatment. Microscopy or malaria Rapid Diagnostic Tests can be used, however in rural African settings microscopy is often unavailable. The process of diagnosis is based on fever detection, often people were presumably administered antimalarial drugs. Because of this, conducting a more rapid diagnostic test that can achieve fast and early diagnosis is recommended as a first step and active surveillance to the control of malaria [3]. The acceptance and use of rapid diagnostic test by community health workers may ease diagnosis process in local malaria-endemic areas characterized by limited facilities and health workers [4]. However, there is very few evidence and studies carried in malaria endemic areas to inform policy makers on the specificity and sensitivity of these RDTs. In aged patients, increase in malaria transmission and lack of symptoms were suggested to affect specificity and sensitivity of RDTs. This in other words can give rise to over- or under-diagnosis of the malaria disease [2] [5]-[10]. As a result, there is little information on the efficacy of rapid diagnostic tests in malaria diagnosis of adults. Therefore this study assessed the efficacy of rapid diagnostic test in the diagnosis of malaria among adults as compared to microscopy in a hospital in Imo state, south eastern Nigeria.

\section{Materials and Methods}

\subsection{Study Design}

The study was conducted from August to September 2018 using a cross sectional study design.

\subsection{Area of Study}

This study was conducted in Umezurike hospital located in Owerri municipal 
local government area of Imo State. The hospital is a private hospital that provides a wide range of medical and support services. Owerri is a commercial city in the south-East of Nigeria. The people are farmers and small scale industrial activities dominate the socio-economy of the inhabitants in the area. Owerri is lying between latitude of 5.483 and longitude of 7.033. It is also bordered by the Otamiri River to the east and Nworie River to the south. Owerri is located in the humid tropical climate with a mean annual rainfall of about $2500 \mathrm{~mm}$ and mean annual temperature of $29^{\circ} \mathrm{C}$. Relative humidity is high during the rainy season and malaria is endemic in these areas during this period.

\subsection{Sample Size}

A total of 110 consenting patients comprising of both males and females who were attending the outpatient of Umezurike hospital within the period of the study (August-September 2018) were recruited for the study.

\subsubsection{Inclusion Criteria}

Adult patients ( $\geq 18$ years) that were clinically suspected to have malaria, that requested for a malaria test and given consent were enrolled in the study. The criteria for the guess of clinical malaria included fever, headache, weakness/body ache and vomiting/nausea.

\subsubsection{Exclusion Criteria}

Patients were excluded if they declined to participate. Also, patients with history of anti-malaria drugs or herbal remedies in the preceding two weeks were excluded from the study. Participants with severe clinical condition needing urgent care were also excluded from the study.

\subsection{Method of Data Collection}

Blood samples were collected from the participants by a trained laboratory scientist for RDT testing and microscopy examination.

\subsubsection{RDT Procedure}

The patient's number was written on the cassette. The finger that was pricked was cleaned using alcohol swab and allowed to dry. Blood was obtained with a capillary tube for testing malaria parasite using SD Bioline malaria HRP-2. $5 \mu$ of blood collected from the patient was deposited on the RDT cassette and 4 drops of buffer was added to facilitate the blood flow through the nitrocellulose. The result was obtained after 15 minutes following the manufacturer's instructions. The cassette had two lines comprising of a control line that showed the validity of the test, and HRP-2 line that indicated an infection with Plasmodium falciparum. Absence of the infection line with the appearance of control line only indicated no infection with the parasite (Figure 1).

\subsubsection{Microscopy Procedure}

Smears for Thick films were made from the fresh blood samples collected from 


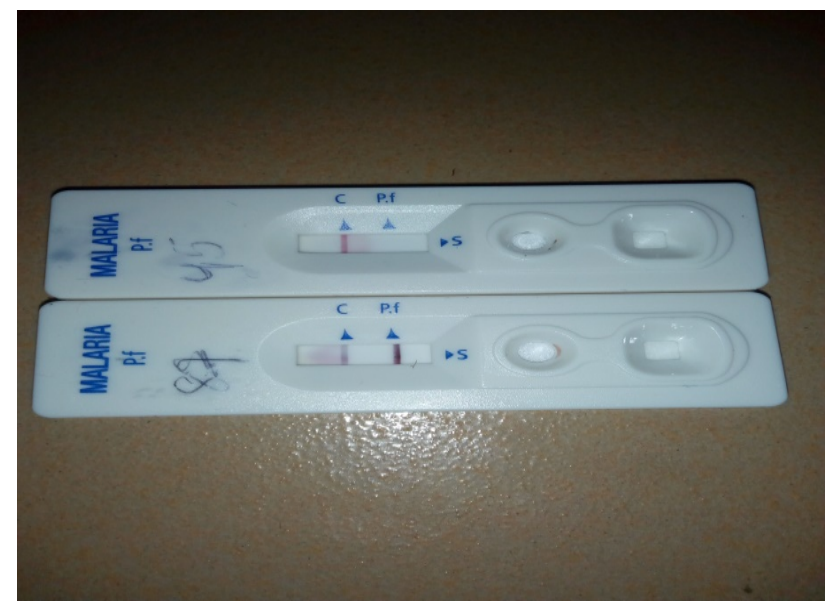

Figure 1. Blood analysis with SD Bioline malaria HRP-2 RDT.

all patients. The slides samples were air dried, and marked with Giemsa stain before the smears were examined for the presence of malaria parasites under light microscopy at a magnification of $\times 100$ by a laboratory scientist (Figure 2 ).

\subsection{Method of Data Analysis}

Descriptive statistics (frequency distribution and percentage) were used. Data generated were analyzed using Chi-square test at $5 \%$ level of significant using Statistical Package for Social Sciences (SPSS) Version 21.

\subsection{Ethical Approval}

Permission to conduct the study was obtained from the Chief Medical Director of the Hospital. During the data collection, Respondents were assured of confidentiality of information. A verbal informed consent was obtained from each of the respondents before collecting their sample.

\section{Results}

Socio-demographic characteristics of the patients

A total of 110 adults of different ages were recruited for the study. There were 63 (57.3\%) females and 47 (42.7\%) males. Their ages scaled from 18 - 79 years and the mean age was $37.2 \pm 15.3$. As shown in Table 1 , those in the age range of 18 - 33 constituted the highest number (49\%).

\subsection{Efficacy of RDT in the Diagnosis of Malaria Using Microscopy as a Standard}

Table 2 displayed the accuracy of RDT in the diagnosis of malaria using microscopy as a gold standard. Microscopy was positive in 107 (97.3\%), and RDT was positive in $32(100 \%)$ of the adult, while $3(2.7 \%)$ of those negative by microscopy were also negative by RDT. The accuracy of microscopy and RDT when compared was not significant $\left(P=0.261, \chi^{2}=1.262\right)$. False positive was $0.0 \%$ while false negative was $96.2 \%$. 


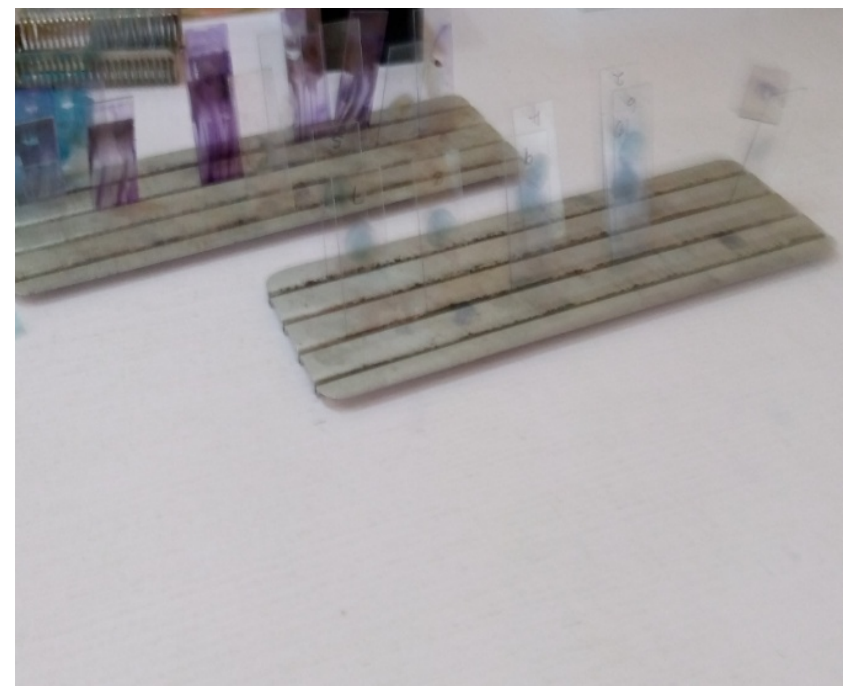

Figure 2. Blood analysis with Giemsa stain ready to be examined under microscope.

Table 1. Sex and age distribution of the respondents.

\begin{tabular}{ccc}
\hline Sex & Frequency & Percentage (\%) \\
\hline Female & 63 & 57.3 \\
Male & 47 & 42.7 \\
Total & 110 & 100.0 \\
Age group (years) & & \\
$18-33$ & 54 & 49.1 \\
$34-48$ & 33 & 30.0 \\
$49-63$ & 14 & 12.7 \\
$64-79$ & 9 & 8.2 \\
Total & 110 & 100 \\
\hline
\end{tabular}

Table 2. Comparison between rapid diagnostic test and microscopy results.

\begin{tabular}{cccc}
\hline & \multicolumn{3}{c}{ Microscopy n (\%) } \\
\hline PDT n (\%) & Nositive & Togative & \\
Positive & $32(100.0)$ & $0(0.0)$ & $32(100.0 \%)$ \\
Negative & $75(96.2)$ & $3(3.8)$ & $78(100.0 \%)$ \\
Total & $107(97.3)$ & $3(2.7)$ & $110(100.0 \%)$ \\
\hline
\end{tabular}

$\mathrm{P}=0.261, \chi^{2}=1.262$.

\subsection{The Validity of RDT Using Microscopy as a Standard}

When compared with the microscopy, RDT had a sensitivity of $29.9 \%(32 / 107)$ and a specificity of $100 \%(3 / 3)$. The positive predictive value was $100 \%(32 / 32)$ and negative predictive value of $3.85 \%(3 / 78)$ as shown in (Table 3 ). 
Table 3. Diagnostic performance of RDTs compared with microscopy.

\begin{tabular}{cc}
\hline Test characteristics & SD Bioline (for P. falciparum) \% \\
\hline Sensitivity & 29.9 \\
Specificity & 100 \\
Positive predictive value & 100 \\
Negative predictive value & 3.85 \\
\hline
\end{tabular}

\section{Discussion}

This study investigated the test performance of two routine malaria diagnostic methods (microscopy technique and Rapid Diagnostic Test (RDT)). The patients were dominated by female gender. This indicated that female participants were highly infected with malaria parasite than their male counterpart. This is in congruent with previous studies conducted by Kalu [11] and Ibekwe [12] in South-Eastern Nigeria, where females were observed to be more infected than males. Olatunji [13] also recorded more prevalence of malaria infection in females than in males. However, the results contradict reports of Adeyemo et al. [14] and Ruquayyah et al. [15] that showed more prevalence of malaria infection among male participants than the female. More than half of the participants were within the age bracket of 18 - 33 years. This demonstrated that transmission was higher among the youths than the elderly. This is in line with the study of Enitan et al. [16] who reported higher prevalence of $P$. falciparum malaria infection in subjects within 16 - 25 years age bracket. In similar study, Adesina [17] reported a higher rate of malaria in 17 - 19 years age bracket of students of University of Maiduguri, North-Eastern Nigeria.

The study also measured the discriminatory accuracy of the RDTs against microscopy using sensitivity and specificity of the apparatuses. The sensitivity and specificity were $29.9 \%$ and $100 \%$ respectively. Lower rate of sensitivity of RDT was shown in this study compared to its stated value suggesting a high level of false negative result which was not anticipated [18]. Lower sensitivity was observed for the RDT when compared to $88.6 \%$ sensitivity reported by Mahende et al. [19] in Tanzania. The reading was also lower than that reported in a similar study in Nigeria by Ojurongbe et al. [20] which had 62.3\%. However, Garba et al. [21] observed a very low sensitivity (9.09\%) in a study conducted in Gusau Nigeria in infants under the age of five. The accuracy of RDTs diagnosis can be affected by numerous factors ranging from storage humidity, temperature, product quality and end users' operation [22]. This low sensitivity recorded in this study can be disadvantageous as it will hinder control intervention due to some portion of the infected population being left untreated especially when RDT is the only available malaria diagnosis tool. This may result in critical implications in transmission, health and possibly mortality. Good sensitivity and a negative RDT result would allow malaria to be ruled out, hence avoiding unnecessary presumptive treatment in any area where this technique is used [23] [24]. 
As recommended by [25], appropriate and suitable outcome of mRDT should demonstrate high sensitivity of $95 \%$. Higher (100\%) specificity recorded in this study is in line with the study of Ilesanmi et al. [26] in Ibadan Nigeria where $99.6 \%$ specificity was observed. The specificity rating of $100 \%$ was also reported in the study of Awortu et al. [27] in Port Harcourt, Nigeria. Lower specificities of $56.26 \%$ and $46.7 \%$ were however reported in Nigeria and western Uganda by Enebeli et al. [28] and Murungi et al. [29] respectively.

However, although microscopy is regarded as the gold standard, there could still possibility of human error which could be the reason for the gap. Thus the high specificity will make the cost of malaria affordable and thereby enhancing the number of non-infected individuals who would have been miss-out, hence the need for proper case definition and care.

The RDT gave positive and negative predictive value of $100 \%$ and $3.98 \%$ respectively. The positive predictive value of $100 \%$ obtained in this study is the same with [30] findings, and this outcome implies that any individual who tested positive using this RDT is expected to be malaria positive when tested with microscopy. Nevertheless, the prevalence of malaria disease among the tested population influence positive and negative predictive values. Also the reason why high positive predictive value was recorded in this study may be because of the prevalence of malaria in the study area.

Compared to microscopic test, the RDT used in this study has the potential of detecting more negative cases and less positive cases. According to [30] the cause of lower positivity rates could be as result of external factors which might affect the stability of the RDT. These factors include exposure to extreme temperatures which has been reported to be an utmost contributor to poor performance of rapid diagnosis tests, particularly during conveyance and storage.

\section{Conclusion}

The study showed that microscopy performance is extremely high compared to RDT in the diagnosis of malaria in adults. Therefore, microscopy remains the standard for malaria testing. However, the drawbacks of this method may affect the pace of distribution of standard services to the patients. Thus, RDT can still serve as the first screening test for malaria diagnosis in rural areas.

\section{Recommendations}

Microscopy is recommended, if available to be done for every patient suspected of having malaria with negative RDT in other not to miss out people with the disease as it remains the gold standard for malaria diagnosis. More studies using a large sample size with this specific RDT brand are also recommended to be carried out in the diagnosis of malaria while comparing it with microscopy.

\section{Limitations of the Study}

The sample size enrolled for this study was determined within the short period 
of recruitment which was one month. The pattern of the outcome may have a slight difference change with an increased number of participants. Furthermore, the choice of a study area as a result of the availability of required health facilities may be doubted as not being a characteristic of the population as a whole.

\section{Acknowledgements}

The authors wish to thank the Management and Staff of Umezurike Hospital Imo state South Eastern Nigeria. All the participants who participated in this study are acknowledged.

\section{Competing Interests}

The authors declare that they have no competing interests.

\section{Consent for Publication}

Not applicable.

\section{Funding}

No funding was received.

\section{References}

[1] Center for Disease Control and Prevention (2010) About Malaria.

[2] Reyburn, H., Mbakilwa, H., Mwangi, R., Mwerinde, O., Olomi, R., Drakeley, C. and Whitty, C.J. (2007) Rapid Diagnostic Tests Compared with Malaria Microscopy for Guiding Outpatient Treatment of Febrile Illness in Tanzania: Randomised Trial. British Medical Journal, 334, 403. https://doi.org/10.1136/bmj.39073.496829.AE

[3] Wongsrichanalai, C., Barcus, M.J., Muth, S., Sutamihardja, A. and Wernsdorfer, W.H. (2007) A Review of Malaria Diagnostic Tools: Microscopy and Rapid Diagnostic Test (RDT). American Journal of Tropical Medical Hygiene, 77, 119-127. https://doi.org/10.4269/ajtmh.2007.77.119

[4] Harvey, S.A., Jennings, L., Chinyama, M., Masaninga, F., Mulholland, K. and Bell, D.R. (2008) Improving Community Health Worker Use of Malaria Rapid Diagnostic Tests in Zambia: Package Instructions, Job Aid and Job Aid-plus-Training. Malaria Journal, 7, 1475-2875. https://doi.org/10.1186/1475-2875-7-160

[5] Swarthout, T.D., Counihan, H., Senga, R.K.K. and van den Broek, I. (2007) Paracheck-Pf Accuracy and Recently Treated Plasmodium falciparum Infections: Is There a Risk of Over-Diagnosis? Malaria Journal, 6, 58. https://doi.org/10.1186/1475-2875-6-58

[6] Abeku, T.A., Kristan, M., Jones, C., Beard, J., Mueller, D.H., Okia, M., Rapuoda, B., Greenwood, B. and Cox, J. (2008) Determinants of the Accuracy of Rapid Diagnostic Tests in Malaria Case Management: Evidence from Low and Moderate Transmission Settings in the East African Highlands. Malaria Journal, 7, 202. https://doi.org/10.1186/1475-2875-7-202

[7] Hopkins, H., Bebell, L., Kambale, W., Dokomajilar, C., Rosenthal, P.J. and Dorsey, G. (2008) Rapid Diagnostic Tests for Malaria at Sites of Varying Transmission Intensity in Uganda. Journal of Infectious Disease, 197, 510-518. https://doi.org/10.1086/526502 
James, S.P. and Tate, P. (2004) Exo-Erythrocytic Schizogony in Plasmodium gallinaceum Brumpt. Parasitology, 30, 128-138. https://doi.org/10.1017/S0031182000010891

[8] Harris, I., Sharrock, W.W., Bain, L.M., Gray, K.A., Bobogare, A., Boaz, L., Lilley, K., Krause, D. and Vallely, A. (2010) A Large Proportion of Asymptomatic Plasmodium Infections with Low and Sub-Microscopic Parasite Densities in the Low Transmission Setting of Temotu Province, Solomon Islands: Challenges for Malaria Diagnostics in an Elimination Setting. Malaria Journal, 9, 254.

https://doi.org/10.1186/1475-2875-9-254

[9] Laurent, A., Schellenberg, J., Shirima, K., Ketende, S.C., Alonso, P.L., Mshinda, H., Tanner, M. and Schellenberg, D. (2010) Performance of HRP-2 Based Rapid Diagnostic Test for Malaria and Its Variation with Age in an Area of Intense Malaria Transmission in Southern Tanzania. Malaria Journal, 9, 294.

https://doi.org/10.1186/1475-2875-9-294

[10] Mtove, G., Nadjm, B., Amos, B., Hendriksen, I.C.E., Muro, F. and Reyburn, H. (2011) Use of an HRP2-Based Rapid Diagnostic Test to Guide Treatment of Children Admitted to Hospital in a Malaria-Endemic Area of North-East Tanzania. Tropical Medicine and International Health, 16, 545-550. https://doi.org/10.1111/j.1365-3156.2011.02737.x

[11] Kalu, M.K., Nwogo, A.O., Onyemachi, F. and Otuchristi, G.A. (2012) Comparative Study of the Prevalence of Malaria in Aba and Umuahia Urban Areas of Abia State, Nigeria. Research Journal of Parasitology, 7, 17-24. https://doi.org/10.3923/jp.2012.17.24

[12] Ibekwe, A.C., Okonko, I.O., Onunkwo, A.I., Ogun, A.A. and Udeze, A.O. (2009) Comparative Prevalence Level of Plasmodium in Freshmen (First Year Students) of Nnamdi Azikwe University in Akwa, Southern-Eastern, Nigeria. Malaysian Journal of Microbiology, 5, 51-54. https://doi.org/10.21161/mjm.16409

[13] Olatunji, M.K., Olugbenga, A.M., Yetunde, A.O. and Tolulope, O.O. (2017) Comparative Prevalence of Plasmodium falciparum Malaria in Patients Attending Okelele Health Center, Okelele, Ilorin, Nigeria. India Journal of Health Sciences and Biomedical Research, 10, 57-62. https://doi.org/10.4103/2349-5006.198590

[14] Adeyemo, F.O., Okpala, P.U., Oyana, E.N. and Imoukhuede, M.O. (2014) Malaria Infection amongst Students of the University of Benin, Edo State, Nigeria. International Journal of Recent Scientific Research, 5, 1529-1532.

[15] Ruquayyah, M.H., Nock, I.H., Ndams, S.I. and George, B.D.J. (2017) Investigating the Prevalence and Intensity of Plasmodium falciparum Infection and Two Methods of Malaria Diagnosis in North-Western Nigeria. International Journal of Tropical Disease and Health, 23, 1-8. https://doi.org/10.9734/IJTDH/2017/28884

[16] Enitan, S.S., Emmanuel, I., Adejumo, E.N., Olayimika, K.A., Gideon, T.F. and Adedoyin, O.A. (2019) Assessment of Rapid Diagnostic Test and Microscopy in the Detection of Plasmodium falciparum Malaria Infection among Young Adults in South-Western Nigeria. South Asian Journal of Parasitology, 2, 1-21.

[17] Adesina, O.O. (2013) Subclinical Malaria Infection among University of Maiduguri Students: Prevalence and Parasite Density. BOMJ, 10, 6-10.

[18] Oyeyemi, O.T., Ogunlade, A.F. and Oyewole, I.O. (2015) Comparative Assessment of Microscopy and Rapid Diagnostic Test (RDT) as Malaria Diagnostic Tools Comparative Assessment of Microscopy and Rapid Diagnostic Test (RDT) as Malaria Diagnostic Tools. https://doi.org/10.3923/jp.2015.120.126

[19] Mahende, C., Billy, N., John, L., Tai-Soon, Y., Paminus, L., Martha, L., Bruno, M. 
and Zul, P. (2016) Performance of Rapid Diagnostic Test, Blood-Film Microscopy and PCR for the Diagnosis of Malaria Infection among Febrile Children from Korogwe District, Tanzania. Malaria Journal, 15, 391. https://doi.org/10.1186/s12936-016-1450-Z

[20] Ojurongbe, O., Adegbosin, O.O., Taiwo, S.S., Alli, O.A., Olowe, O.A., Ojurongbe, T.A., Oloyede, S.B. and Oluwaseyi, A.A. (2013) Assessment of Clinical Diagnosis, Microscopy, Rapid Diagnostic Tests, and Polymerase Chain Reaction in the Diagnosis of Plasmodium falciparum in Nigeria. Malaria Research and Treatment, 2013, Article ID: 308069. https://doi.org/10.1155/2013/308069

[21] Garba, B.I., Muhammad, A.S., Musa, A., Edem, B., Yusuf, I., Bello, N.K., Adeniji, A.O. and Kolawole, T. (2006) Diagnosis of Malaria: A Comparison between Microscopy and Rapid Diagnostic Test among Under-Five Children at Gusau, Nigeria. Sub-Saharan African Journal of Medicine, 3, 96-101. https://doi.org/10.4103/2384-5147.184371

[22] Endeshaw, T., Gebre, T., Ngondi, J., Patricia, M.G., Estifanos, B., Ejigsemahu, S.Y., Ayele, B., Yohannes, G., Teferi, T., Messele, A., Zerihun, M., Genet, A., Mosher, A.W., Emerson, P.M. and Richards, F.O. (2008) Evaluation of Light Microscopy and Rapid Diagnostic Test for the Detection of Malaria under Operational Field Conditions: A Household Survey in Ethiopia. Malaria Journal, 7, Article 118.

https://doi.org/10.1186/1475-2875-7-118

[23] Marx, A., Pewsner, D., Egger, M., Nüesch, R., Bucher, H.C., Genton, B., Hatz, C. and Jüni, P. (2005) Meta-Analysis: Accuracy of Rapid Tests for Malaria in Travellers Returning from Endemic Areas. Annals of Internal Medicine, 142, 836-846. https://doi.org/10.7326/0003-4819-142-10-200505170-00009

[24] Jelinek, T., Grobusch, M.P. and Nothdurft, H.D. (2000) Use of Dipstick Tests for the Rapid Diagnosis of Malaria in Nonimmune Travellers. Journal of Travel Medicine, 7, 175-179. https://doi.org/10.2310/7060.2000.00055

[25] WHO (2011) Malaria Rapid Diagnostic Test Performance: Summary Results of WHO Malaria RDT Product Testing: Rounds 1-3 (2008-2011). World Health Organization, Geneva.

http://www2.wpro.who.int/NR/rdonlyres/005E574B-FFCD-484C-BEDE-C580324A C2CF/0/RDTMalariaRd3_Summary_FINAL11Oct.pdf

[26] Ilesanmi, R.I., Oluwasogo, A.O., Oluwasegun, T.A., Ayodele, O.I., Hyacinth, E. and Abimbola, O.A. (2017) Comparative Assessment of Malaria Rapid Diagnostic Tests (RDT) in Ibadan, Nigeria. Malaria Journal, 8, 17.

[27] Awortu, J.Z., Uko, E.K., Buseri, F.I. and Awortu, J.T. (2007) Field Evaluation of SD Bioline Rapid Malaria Diagnostic Test Kit among Asymptomatic Malaria-Infected Children in Port Harcourt, Nigeria. Research Journal of Parasitology, 2, 39-44. https://doi.org/10.3923/jp.2007.39.44

[28] Enebeli, U.U., Amadi, A.N., Okechukwu, K.I., Oparaocha, E.T., Nwoke, E.A., Oti, N.N., Ibe, S.N.O., Chukwuocha, U.M., Nwufo, C.R., Amadi, C.O. and Esomonu, I. (2019) A Comparison of the Rapid Diagnostic Test and Microscopy for Malaria Diagnosis in Children under Five in Abia State, Nigeria. International Journal of Research and Scientific Innovation, 6, 199-202.

[29] Murungi, M., Fulton, T., Reyes, R., Matte, M., Ntaro, M., Mulogo, E. and Buyce, R. (2017) Improving the Specificity of Plasmodium falciparum Malaria Diagnosis in High-Transmission Settings with a Two-Step Rapid Diagnostic Test and Microscopy Algorithm. Journal of Clinical Microbiology, 55, 1540-1549.

https://doi.org/10.1128/JCM.00130-17 
[30] Albertini, A., Lee, E., Coulibaly, S.O., Sleshi, M., Faye, B. and Mationg, M.L. (2012) Malaria Rapid Diagnostic Test Transport and Storage Conditions in Burkina Faso, Senegal, Ethiopia and the Philippines. Malaria Journal, 11, 406.

https://doi.org/10.1186/1475-2875-11-406 